\title{
Gender discrimination and other factors affecting Full Immunization Coverage (FIC) in 59 low performing blocks of Bihar
}

\section{M Singh ${ }^{1}$, Abhishek Mishra ${ }^{2}$, Neeraj Agarwal ${ }^{3}$, Arshad Ayub ${ }^{4}$, Shradha Mishra ${ }^{5}$, Pallavi Lohani ${ }^{6}$}

${ }^{1}$ Professor, Department of Community \& Family Medicine, All India Institute of Medical Science, Patna; ${ }^{2}$ Assistant professor, Department of Community \& Family Medicine, All India Institute of Medical Science, Patna; ${ }^{3}$ Professor, Department of Community \& Family Medicine, All India Institute of Medical Science, Patna; ${ }^{4}$ Senior Resident, Department of Community \& Family Medicine, All India Institute of Medical Science, Patna; ${ }^{5}$ Senior Resident, Department of Community \& Family Medicine, AlIMS, Patna; ${ }^{6}$ Senior Resident, Department of Community \& Family Medicine, All India Institute of Medical Science, Patna

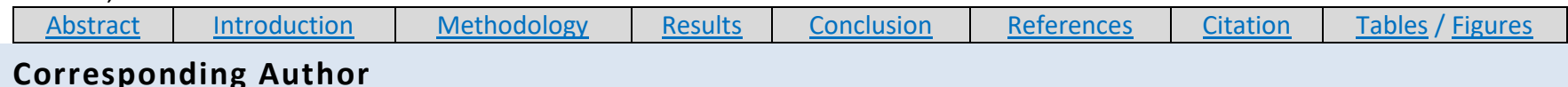

\begin{tabular}{|l|l|}
\hline Dr. Arshad Ayub, Senior Resident, Department of Community \& Family Medicine, All India Institute of \\
Medical Science,Phulwari Sharif, Patna, Bihar - 801507 \\
E Mail ID: drarshadayubcommed@gmail.com
\end{tabular}

\section{Citation}

Singh CM, Mishra A, Agarwal N, Ayub A, Mishra S, Lohani P. Gender discrimination and other factors affecting Full Immunization Coverage (FIC) in 59 low performing blocks of Bihar. Indian J Comm Health. 2020;32(1):101-107.

Source of Funding: UNICEF Conflict of Interest: None declared

\section{Article Cycle}

Received: 30/12/2019; Revision: 15/01/2020; Accepted: 17/03/2020; Published: 31/03/2020

This work is licensed under a Creative Commons Attribution 4.0 International License.

\section{Abstract}

Background: Routine childhood immunization has proven to be among the most practical and most cost-effective health interventions. The full immunization coverage (FIC) has increased, still it is less. Especially in the low performing blocks of Bihar , it is less than $70 \%$.There are various factors responsible for less FIC including gender discrimination also which is still hidden in the society. Hence this study was done to find out the FIC in Bihar with associated factors including gender discrimination. Objectives: To find out the various associated factors affecting FIC and to find out gender discrimination (if any) in FIC in different districts of Bihar. Methodology: Two stage cluster sampling with Probability Proportional to size Sampling (PPS) was used as per Study protocol. The study was conducted in 59 low-performing blocks of Bihar where the full immunization coverage was less than $70 \%$. The survey was conducted in 59 blocks. From each block, 30 clusters (Villages) were selected. As a convention, 7 children of age group 12- 23 months were selected from each cluster. Thus, data collection was done for a total of 12,390 children.A structured questionnaire was formulated on the basis of WHO coverage evaluation format. Web based Application SDRC kit was used for data collection while SPSS v. 20 was used for analysis. Results: FIC was found to be $60.81 \%$, it was higher for the rural clusters, general caste, Hindus when compared to urban clusters, SC and other castes, and Muslim religion respectively. For 1st child FIC was highest (66.8\%) and was lesser for females. A coverage ratio (female to male) was found to be less than 1 for most of the districts. Conclusion: There are considerable inequities in full immunization by various individual (birth order, gender, birth weight), social (religion, caste), and societal (health care facility and cluster type) characteristics. In general, the ratio (female/male) remains less than 1 for most of the districts.

\section{Keywords}

Full Immunization Coverage; Gender Discrimination; Coverage Ratio; Gender Inequality

\section{Introduction}

Worldwide, tremendous progress has been reported in the reduction in child mortality and Routine childhood immunization has proven to be among the most practical and most cost-effective health interventions. $(1,2,3)$ The scenario of routine child immunization in India is changing rapidly. $(4,5)$ The central government declared 2012-2013 to be a period of intensification in routine immunization, with a priority on difficult to reach areas, urban slums and migrant and mobile communities.(6) Subsequently, India's Ministry of Health and Family Welfare launched Mission Indradhanush. in December 2014. The aims of this initiative were to ensure that all children are fully vaccinated against seven vaccine-preventable diseases (VPDs) before they reach an age of two years and vaccinate at least $90 \%$ of pregnant women against tetanus. $(7,8)$ General improvements in the delivery of 
routine immunization services were also critical in the successful efforts to interrupt polio transmission in India and remain a key component in attempts to eliminate measles from the country by 2020.(9) Despite universal immunization program, being operational for the past 30 years, only $65 \%$ children in India receive all vaccines during their first year of life. It is estimated that annually, more than 89 lakh children in the country do not receive all vaccines that are available under the universal immunization program-the highest number compared with any other country in the world.(10)

Demographic barriers (minority ethnicity, parents' lack of education, and low socioeconomic status), populations living in difficult-to-reach areas, programmatic challenges such as vaccine stock-outs, and conflict are the factors which prevent certain children from receiving the benefits of being fully vaccinated (13). At district or national levels, program costs and insufficient political will also contribute to problems with vaccine access and completion of vaccination series (14).

To improve accessibility to vaccination, steps are needed to ensure that hard-to-reach populations are identified and that vaccination sessions are made consistently accessible. Program managers need to use effective vaccine management practices to avoid stock-outs, and health workers need to be available and well trained to provide acceptable services to the community (15). The role of gender and sex disparities in immunization coverage has been subject to much debate in recent years with terminology often used interchangeably. The GAVI Alliance (GAVI) has recently entered into this discussion and set a gender policy to focus attention on gender related barriers to immunization.(16)The present study being a part of the coverage evaluation of routine immunization, also tries to analyze the gender inequalities/discrimination in the low performing blocks of Bihar.

With the aim of improving the quality of immunization services and coverage, the State Health Society, Bihar in collaboration with UNICEF and Community Medicine Department of 06 medical colleges of Bihar started regular Supportive Supervision of Routine Immunization (SSRI) Program for the period of 3 years (Nov 2014 to Dec 2017). The Department of Community and Family Medicine (C\&FM), AIIMS Patna has been functioning as the nodal center for SSRI Program, which ensures quality supervision of Immunization sites.

\section{Aims \& Objectives}

\section{Primary Objective}

1. To calculate and assess the Full Immunization coverage of routine immunization among children in age group 12- 23 months belonging to low performing blocks.

\section{Secondary objective}

1. To find out the various associated factors affecting FIC

2. To find out gender discrimination (if any) in FIC in different districts of Bihar.

\section{Material \& Methods}

The methodology is done in accordance with WHO guidelines (18) and it can be summarized as follows

Study type: Community based, Cross Sectional, Study Area : 59 low performing blocks, selected villages in those blocks.

Study population: 12-23 month year old children, Study Duration: One month (30 days)

Sampling:

Two stage cluster sampling with Probability Proportional to size Sampling (PPS) was used as per Study protocol. The study was conducted in 59 low-performing blocks of Bihar where the full immunization coverage was less than $70 \%$. The block- wise village details (including population) was obtained from the UNICEF. Thirty villages (Clusters) were taken from each block where study was conducted. From each of selected Blocks the Clusters were taken by Probability proportional to size (PPS) method. First village was selected randomly and the rest twenty- nine were selected using sampling-interval which was calculated on Microsoft Excel.

From each selected cluster, seven households were selected having children in the age- group of 12- 23 months. In the allotted village, at the center of the village, a landmark (temple, mosque, govt. building etc.) was ascertained. A convention of sticking to the left- side was followed. The first household was randomly selected by Currency-method. For the selection of remaining household, house order (House order denotes the number of households to leave for selection of next household) was calculated.

The survey was conducted in 59 blocks. From each block, 30 (Villages) clusters were selected. As a convention, 7 children of age group 12- 23 months were selected from each cluster. Thus, data collection was done for a total of 12,390 children.

\section{Study tools, techniques and manpower:}

A structured questionnaire was formulated on the basis of WHO coverage evaluation format. Apart from the parameters given in the WHO format, Birth weight, Birth Order and Place of vaccination was incorporated in the questionnaire. This was utilized in development of the Web based Application SDRC kit. Pre- testing of the questionnaire and app was carried out before data collection in Kamla Nehru Nagar Slum, R- Block, Patna and Rajvanshi Nagar Slum, Patna. Necessary modifications have been done in the Application after this Pre-testing. The data was automatically entered from SDRC application to excel in the servers and then were analyzed in SPSS V20 and the forest plot was generated in forest 
INDIAN JOURNAL OF COMMUNITY HEALTH / VOL 32 / ISSUE NO 01 / JAN - MAR 2020

[Gender discrimination and...] | Singh CM et al

plot generator by online portal https://www.evidencepartners.com/.

\section{Results}

Out of 12390 data obtained from 59 different blocks, after data cleaning (removing duplicate/incomplete data) a total of 12331 data was analyzed. Around $80 \%$ of the individual data was from rural clusters and $20 \%$ was from Urban clusters. Majority (53.5\%) of the respondents were from OBC caste while $26.85 \%$ were SCs and $13.34 \%$ were General. Around $81.67 \%$ were Hindus and $18.28 \%$ were Muslims. Male children were $53.3 \%$ and females were $46.7 \%$. Full Immunization Coverage is defined as immunization of a child with one dose of Bacille Calmette Guerin (BCG), 3 doses of Diphtheria Pertussis and Tetanus (DPT), Oral Polio Vaccine (OPV), Hepatitis B Vaccine and one dose of Measles vaccine within the age of one year(19).(Table 1)

The above table shows that $63.41 \%$ of the rural population had full immunization coverage while only $50.82 \%$ of the urban population had FIC. The association was highly significant at $p=0.000$. However a study done by Phukan et al shows that Urban population had better FIC (85.9\%) as compared to rural (58.7\%).(20)

Full Immunization coverage was highest (62.9\%) among generals and was lowest i.e. $45.3 \%$ among others. Also it was less $58.8 \%$ among SCs. The difference was statistically significant.

\section{Discussion}

A study done by Jagjivan Babu Geddam et al shows that the "drop-out rates for DPT-measles" which indirectly indicates the FIC, was better in OBC and SC castes ( almost $13 \% \& 18 \%$ ) respectively and ST Caste had $>30 \%$ drop out rate which meant a poor FIC among STs.(21) NFHS-4 data also shows that at National level ST caste has poorer FIC (56\%) as compared to other castes.(11) Although Phukan et al's study shows also a higher rate of FIC in ST caste when compared to SCs (66.7\% and $53.1 \%$ respectively) which is similar to our study.(20) It was clear that FIC was more in Hindus (61.64\%) when compared to Muslims (57.03\%).The association was found to be highly significant $(p=0.000)$. Muslims were also shown to have poorer FIC (55.9\%) in a study done by Phukan et al in Assam.(20)

By observing the association between place of vaccination and full immunization coverage, it was clear that FIC was more $(61.2 \%)$ among those children who were taking vaccination in Govt. centers while it was quite less (49\%) among children who were taking vaccinations in private centers. This association was found to be highly significant $(p=0.000)$. The difference can be attributed to near home and easy to reach govt. facilities and free vaccination provision at govt. facilities. M.R. Francis et al in their study also found that FIC was higher in Govt./public facility (95.1\%) as compared to private facility (4.9\%). (22) NFHS4 data also shows that in Bihar the children taking vaccination in Public health facility is $95.5 \%$ and in private only 3.9\%.(23)(Figure 1)

When the FIC was plotted against individual birth orders it was found that there was a decline in FIC from 1st child to onwards, while it was $66.8 \%$ for the 1 st child , it was $59.5 \%$ for the 2 nd child and was $57.3 \%$ for the 3rd child. Also when the birth order till 5th child was considered against FIC it was found to be significant $(p=<0.001)$. Following table shows the FIC coverage of different birth order children till birth order 5(Table 2)

Our Multiple logistic regression analysis shows that Odds of having FIC in urban areas is 0.57 when compared with rural areas. This difference can be attributed to the better near home (angan-wadi centers \& sub centers) facilities in rural areas as compared to the urban ones. Gender was also included in the model showing Odds for females a little less when compared to males (0.94).Putting Caste in the model shows OBC and ST having almost same odds (0.89 \& 0.96 ) respectively as compared to General Castes , while SC had decreased odds of (0.78) .Muslims were also having lesser Odds (0.91) of having FIC when compared to Hindus. Birth Order groups show that Odds of having FIC is lesser for higher birth order children when compared to those falling in birth order of 1 to 3.In a study done by $A$ Debnath \& N Bhattacharjee, it was observed that immunization status had a strong association with birth order. The negative coefficient $(-0.295)$ indicates that higher birth order had a discouraging effect on child immunization which is similar to our study.(24) However, In another study by M.R. Francis found that the higher birth order had higher Odds of FIC (1.77 for >3 birth order).(22)

The study done by Phukan et al shows a higher odds for males (1.25) ,lesser odds for SC and ST than general , and lesser odds for muslims having full immunization coverage which all are in accordance to the present study.(20)

Considering birth weight of the children, shows that Odds of having FIC definitely increases for higher birth weight babies when compared to babies born with $<1.5 \mathrm{Kg}$. It is was found to be 1.8 for babies of $1500 \mathrm{gm}$ to $2500 \mathrm{gm}$, and was 2.2 for babies of 2500 to 3500 gms.

By observing gender disparities in $\mathrm{RI}$, we tried to incorporate an indicator which is coverage ratio in to the results. Coverage ratio can be defined as the FIC ratio of females and males in any particular district. Hence coverage ratio was calculated according to each district. It was not calculated at block level because it was difficult to put a graph/plot of 59 areas. (Figure 2)

The average coverage ratio is 0.91 for Bihar and it was highest (1.6) in Araria followed by Darbhanga (1.4).The lowest coverage ratio was found in Supaul (0.60).The less immunization coverage for girls is definitely a matter of concern, it somewhere indicates the neglect of girl child in such scenarios. In a study done in Rural Rajasthan, it was also observed that FIC for females were lesser than males.(25) Similarly a study done by Phukan et al in Assam 
shows poor FIC for females (59.3\%) than males (64.6\%).(20)

A Vaccination data of 1279 infants in the age range 1-3 years in West Bengal state was examined from the District Level Household Survey under the Reproductive and Child Health project (2002-2004), full vaccination was $53.0 \%$ among boys and $54.7 \%$ among girls; odds ratio 1.061 (95\% $\mathrm{Cl}$ not given).(26)(Figure $3 \mathrm{~A}$ ) \& (Figure 3B)

After calculating coverage ratio for all the districts, the data was plotted on a forest plot, using the Coverage ratio, $95 \% \mathrm{Cl}$ for that, and weight. Weight was calculated according to the size of data obtained from that particular district (as compared to the whole data),denoted by squares. The overall weight is the over-all size of the study (shown by diamond). The plot shows that in most of the districts the coverage ratio is less than 1 which means a poor immunization coverage

NFHS-3 data shows that among the states of India highest coverage ratio was found in West Bengal (1.04) while lowest was in Punjab (0.87). Bihar was the second lowest (0.88) in terms of FIC coverage ratio.(27) In a study done by $S$ Prinja et al the coverage ratio was 0.99 in Haryana state.(28) which is comparable to our study (coverage ratio 0.91).

\section{Conclusion}

It was observed that there are considerable inequities in full immunization by various individual (birth order, gender, birth weight), social (religion, caste), and societal (health care facility and cluster type) characteristics. In general, girls have worse FIC than boys, overall difference is of $1.5 \%$ but the ratio (female to male) for FIC is as low as 0.6 and is less than 1 in maximum districts which indicates gender discrimination in the region.

Higher birth order infants have lower full immunization coverage, the precise reasons for this have not been elucidated, hence the declining vaccination coverage of higher birth order infants needs further exploration. It is often explained away stating that parents with more children become less vigilant about vaccination. However plausibly speaking, the opposite is expected to be more likely, as experience with caring for first-born infants would better familiarize mothers as well as other family members with the vaccination schedule. A possible reason that has not been explored at all is whether the absence of occurrence of vaccine preventable diseases in first born infants and the community, encourages complacency (or worse resistance) towards vaccination.

Thus, there is a need to encourage mothers of these children to extend the gap between pregnancies so that proper care can be given to all the children equally and there occurs no discrimination between two children.

The study also showed that rural infants have higher coverage than those infants of urban cluster. There is a relationship between religion, caste and full immunization which indicates that religion and caste with better socioeconomic status and education have better FIC. The study actually also revealed that child immunization was less concentrated in Muslims and this inequality negatively contributed around $5 \%$ inequality in immunization. It can be said that concentration of postnatal care and check-ups of newborns towards the richer section positively contributes to unequal access to immunization.

Also the FIC from government immunization centers is better than those of private centers. Reason behind this can be free and easy to access vaccination centers like Aanganwadi, Sub centers and PHCs, major contributor can be Aanganwadi centers which are usually located inside the villages. Also the cost is a factor which plays an important role in the utilization of government immunization centers more than the private institutions.

\section{Recommendation}

As in most of the districts the gender gap remains less (less full immunization in females), it can be said that both the parents should be made aware regarding the importance of full immunization and definitely there is a need for education which in turn can improve things. In a nut shell, some specific short trainings can be designed which tells about the importance of full immunization in the kids of both the genders.

\section{Limitation of the study}

Education of the parents was not taken which although plays an important role in the final outcome of the immunization status of the child.

\section{Relevance of the study}

We tried to find out the coverage ratio of female to male full immunization and got that in most of the districts it is less than 1 (indicates less full immunization in female child) which somehow indicates a neglect towards female child when compared to the males. Also the study tries to highlight the role of high birth order associated with less immunization.

\section{Authors Contribution}

CMS- Concept, design, intellectual content, Manuscript review AM- Design, intellectual content, Manuscript editing, Manuscript review, NA- Concept , design , intellectual content, Manuscript review, AA- Literature search, data analysis, statistical analysis, manuscript preparation, Manuscript editing, SM- Literature search, data analysis, statistical analysis, manuscript preparation, PL- Literature search, data analysis, statistical analysis, manuscript preparation

\section{Acknowledgement}

The authors acknowledge the staff of the All India Institute of Medical Sciences, Patna, the data collectors who made this extensive data collection possible and all the study participants for their cooperation and time. 


\section{References}

1. Merten S, Hilber A, Biaggi C, Secula F, Bosch-Capblanch X, Namgyal $P$, et al. Gender Determinants of Vaccination Status in Children: Evidence from a Meta-Ethnographic Systematic Review. PloS One 2015;10:e0135222.

2. Choudhary M, Solomon R, Awale J, Dey R. Demand-side determinants of timely vaccination of oral polio vaccine in social mobilization network areas of CORE Group polio project in Uttar Pradesh, India. BMC Infect Dis [Internet] 2018 [cited 2019 Jul 24];18. Available from: https://www.ncbi.nlm.nih.gov/pmc/articles/PMC5956729/

3. WHO | Global Vaccine Action Plan 2011-2020 [Internet]. WHO

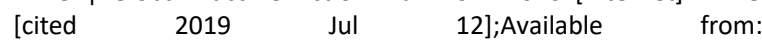
http://www.who.int/immunization/global_vaccine_action_plan/G VAP_doc_2011_2020/en/

4. Vashishtha VM, Kumar P. 50 years of immunization in India: Progress and future. Indian Pediatr 2013;50(1):111-8.

5. Lahariya C. A brief history of vaccines $\&$ vaccination in India. Indian J Med Res 2014;139(4):491.

6. Taneja G, Sagar KS, Mishra S. ROUTINE IMMUNIZATION IN INDIA: A PERSPECTIVE. Indian J Community Health 2013;25(2):188-92.

7. Travasso $C$. Mission Indradhanush makes vaccination progress in India. :1.

8. Bhatnagar P, Gupta S, Kumar R, Haldar P, Sethi R, Bahl S. Estimation of child vaccination coverage at state and national levels in India. Bull World Health Organ 2016;94(10):728-34.

9. Thapa $A B$, Wijesinghe PR, Abeysinghe MRN. Measles elimination by 2020: a feasible goal for the South-East Asia Region? WHO SouthEast Asia J Public Health 2014;3(2):123.

10. Mohapatra I, Kumar A, Mishra K. A study on awareness and utilization of Mission Indradhanush in an urban slum of Bhubaneswar. J Fam Med Prim Care 2018;7(6):1294.

11. India.pdf [Internet]. [cited 2019 Jul 12];Available from: http://rchiips.org/nfhs/pdf/NFHS4/India.pdf

12. SRS_Bulletin-Rate-2017-_May_2019.pdf [Internet]. [cited 2019 Jul 12];Available from: http://censusindia.gov.in/vital_statistics/SRS_Bulletins/SRS_Bullet in-Rate-2017-_May_2019.pdf

13. Rainey JJ, Watkins M, Ryman TK, Sandhu P, Bo A, Banerjee K. Reasons related to non-vaccination and under-vaccination of children in low and middle income countries: findings from a systematic review of the published literature, 1999-2009. Vaccine 2011;29(46):8215-21.

14. Drivers of routine immunization coverage improvement in Africa: findings from district-level case studies [Internet]. [cited $2019 \mathrm{Jul}$ 24];Available https://www.ncbi.nlm.nih.gov/pmc/articles/PMC4353894/
15. Phillips DE, Dieleman JL, Lim SS, Shearer J. Determinants of effective vaccine coverage in low and middle-income countries: a systematic review and interpretive synthesis. BMC Health Serv Res 2017;17(1):681.

16. Hilber AM, Bosch-Capblanch $X$, Schindler C, Beck L, Sécula $F$, McKenzie O, et al. Summary report for SAGE, November 2010. :206.

17. Cutts FT, Izurieta HS, Rhoda DA. Measuring Coverage in $\mathrm{MNCH}$ Design, Implementation, and Interpretation Challenges Associated with Tracking Vaccination Coverage Using Household Surveys. PLOS Med 2013;10(5):e1001404.

18. WHO. Vaccination coverage Cluster Surveys: Reference Manual. 2015;(July):259.

19. A Study to Find Out the Full Immunization Coverage of 12 to 23month old Children and Areas of Under-Performance using LQAS Technique in a Rural Area of Tripura [Internet]. [cited 2019 Jul 25];Available https://www.ncbi.nlm.nih.gov/pmc/articles/PMC5376832/

20. Phukan RK, Barman MP, Mahanta J. Factors Associated with Immunization Coverage of Children in Assam, India: Over the First Year of Life. J Trop Pediatr 2009;55(4):249-52.

21. Immunization uptake and its determinants among the internal migrant population living in nonnotified slums of Hyderabad city, India [Internet]. [cited 2019 Jul 18];Available from: https://www.ncbi.nlm.nih.gov/pmc/articles/PMC6132015/

22. Francis MR, Nuorti JP, Kompithra RZ, Larson H, Balraj V, Kang G, et al. Vaccination coverage and factors associated with routine childhood vaccination uptake in rural Vellore, southern India, 2017. Vaccine 2019;37(23):3078-87.

23. BR_FactSheet.pdf [Internet]. [cited 2019 Jul 18];Available from: http://rchiips.org/nfhs/pdf/NFHS4/BR_FactSheet.pdf

24. Debnath A, Bhattacharjee N. WEALTH-BASED INEQUALITY IN CHILD IMMUNIZATION IN INDIA: A DECOMPOSITION APPROACH. J BiosOC Sci 2018;50(3):312-25.

25. Ganguly E, Gupta R, Widge A, Reddy RP, Balasubramanian K, Reddy PS. Increasing Full Child Immunization Rates by Government Using an Innovative Computerized Immunization Due List in Rural India. Inq J Health Care Organ Provis Financ 2018;55:004695801775129.

26. Mathew JL. Inequity in childhood immunization in India: A systematic review. Indian Pediatr 2012;49(3):203-23.

27. Corsi DJ, Bassani DG, Kumar R, Awasthi S, Jotkar R, Kaur N, et al. Gender inequity and age-appropriate immunization coverage in India from 1992 to 2006. BMC Int Health Hum Rights 2009;9(Suppl 1):S3.

28. Prinja S, Monga D, Rana SK, Sharma A, Dalpath S, Bahuguna P, et al. District Level Analysis of Routine Immunization in Haryana State: Implications for Mission Indradhanush under Universal Immunization Programme. Indian J Community Med Off Publ Indian Assoc Prev Soc Med 2018;43(3):209-14

\section{Tables}

TABLE 1 ASSOCIATION OF FIC WITH DIFFERENT SOCIO-DEMOGRAPHIC CHARACTERS

\begin{tabular}{|c|c|c|c|c|}
\hline & FIC & & Total & \multirow{5}{*}{$P=0.000$} \\
\hline Type of Cluster & Yes & No & & \\
\hline Rural & 6205 (63.41\%) & 3580 (36.58\%) & 9785 (79.35\%) & \\
\hline Urban & $1294(50.82 \%)$ & $1252(49.17 \%)$ & $2546(20.65 \%)$ & \\
\hline Total & 7499 (60.81\%) & 4832 (39.19\%) & $12331(100 \%)$ & \\
\hline \multirow[t]{2}{*}{ Caste } & \multicolumn{2}{|l|}{ FIC } & \multirow[t]{2}{*}{ Total } & \multirow{8}{*}{$P=0.000$} \\
\hline & Yes & No & & \\
\hline General & 1035 (62.9\%) & $610(37.1 \%)$ & 1645 (13.34\%) & \\
\hline OBC & $4094(62.0 \%)$ & $2511(38.0 \%)$ & 6605 (53.5\%) & \\
\hline Other & $143(45.3 \%)$ & $173(54.7 \%)$ & $316(2.56 \%)$ & \\
\hline SC & 1946 (58.8\%) & $1366(41.2 \%)$ & $3312(26.85 \%)$ & \\
\hline ST & $281(62.0 \%)$ & $172(38.0 \%)$ & $453(3.67 \%)$ & \\
\hline Total & 7499 & 4832 & 12331 & \\
\hline \multirow[t]{2}{*}{ Religion } & \multicolumn{2}{|l|}{ FIC } & Total & \multirow{2}{*}{$P=0.000$} \\
\hline & Yes & No & & \\
\hline
\end{tabular}




\begin{tabular}{|c|c|c|c|c|}
\hline Hindu & $6208(61.64 \%)$ & $3863(38.36 \%)$ & $10071(81.67 \%)$ & \multirow{11}{*}{$P<0.0001$} \\
\hline Muslim & $1286(57.03 \%)$ & $969(42.97 \%)$ & $2255(18.28 \%)$ & \\
\hline Other & $5(100 \%)$ & $0(100 \%)$ & $5(0.04 \%)$ & \\
\hline Total & 7499 & 4832 & 12331 & \\
\hline \multirow[t]{2}{*}{ Birth Order } & \multicolumn{2}{|l|}{ FIC } & \multirow[t]{2}{*}{ Total } & \\
\hline & Yes & No & & \\
\hline 1 & 2119 (66.8\%) & $1052(33.2 \%)$ & $3171(100 \%)$ & \\
\hline 2 & $2632(59.5 \%)$ & $1790(40.5 \%)$ & $4422(100 \%)$ & \\
\hline 3 & 1669 (57.3\%) & 1245 (42.7\%) & $2914(100 \%)$ & \\
\hline 4 & $671(60.2 \%)$ & $444(39.8 \%)$ & $1115(100 \%)$ & \\
\hline 5 & $238(56.5 \%)$ & $183(43.5 \%)$ & $421(100 \%)$ & \\
\hline \multirow[t]{2}{*}{ Gender } & \multicolumn{2}{|l|}{ FIC } & \multirow[t]{2}{*}{ Total } & \multirow{4}{*}{$p=0.09$} \\
\hline & Yes & No & & \\
\hline Male & $4043(61.5 \%)$ & $2531(38.5 \%)$ & $6574(53.31 \%)$ & \\
\hline Female & $3456(60.0 \%)$ & $2301(40.0 \%)$ & $5757(46.69 \%)$ & \\
\hline \multirow[t]{2}{*}{ Place of Vaccination } & \multicolumn{2}{|l|}{ FIC } & \multirow[t]{2}{*}{ Total } & \multirow{6}{*}{$p=0.000$} \\
\hline & Yes & No & & \\
\hline Govt. & 7191 (61.2\%) & $4556(38.8 \%)$ & $11747(100.0 \%)$ & \\
\hline Private & $214(49.0 \%)$ & $223(51.0 \%)$ & $437(100 \%)$ & \\
\hline \multirow[t]{2}{*}{ Both } & $94(63.9 \%)$ & $53(36.1 \%)$ & 147 (100\%) & \\
\hline & 7499 & 4832 & 12331 & \\
\hline
\end{tabular}

TABLE 2 SHOWS THE ODDS RATIO (EXP B) USING MULTIPLE LOGISTIC REGRESSION ANALYSIS FOR FULL IMMUNIZATION COVERAGE

\begin{tabular}{|c|c|c|c|c|}
\hline \multicolumn{2}{|r|}{ Sign } & \multirow[t]{2}{*}{ Exp(B)/OddsR } & \multicolumn{2}{|c|}{ 95\% C.I. for $\operatorname{Exp(B)/OddsR~}$} \\
\hline Caste & & & Lower & Upper \\
\hline OBC & .072 & .899 & .800 & 1.009 \\
\hline SC & .000 & .788 & .692 & .898 \\
\hline ST & .726 & .961 & .770 & 1.200 \\
\hline Others & .000 & .547 & .424 & .705 \\
\hline \multicolumn{5}{|l|}{ Religion } \\
\hline Muslim & .092 & .913 & .821 & 1.015 \\
\hline \multicolumn{5}{|l|}{ Birth Order } \\
\hline 4 to 6 & .414 & .956 & .857 & 1.065 \\
\hline$>7$ & .868 & .970 & .678 & 1.388 \\
\hline \multicolumn{5}{|c|}{ Birth weight } \\
\hline $1500-2499$ & .015 & 1.880 & 1.131 & 3.125 \\
\hline $2500-3499$ & .001 & 2.276 & 1.392 & 3.722 \\
\hline$>3500$ & .469 & 1.199 & .734 & 1.959 \\
\hline \multicolumn{5}{|l|}{ Gender } \\
\hline Female & .117 & .943 & .875 & 1.015 \\
\hline \multicolumn{5}{|c|}{ Type of Cluster } \\
\hline Urban & .000 & .571 & .522 & .625 \\
\hline Constant & .299 & 1.306 & & \\
\hline
\end{tabular}




\section{Figures}

FIGURE 1 VARIATION OF FIC ACCORDING TO THE BIRTH ORDER OF CHILDREN

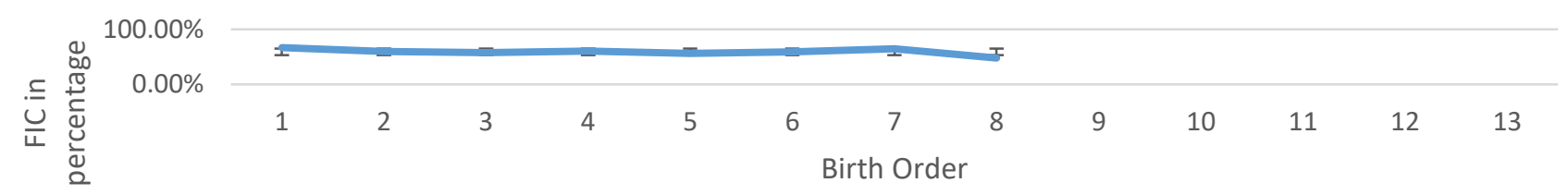

FIC

FIGURE 2 SHOWS THE COVERAGE RATIO OF FIC (FEMALES TO MALES) IN DIFFERENT DISTRICTS

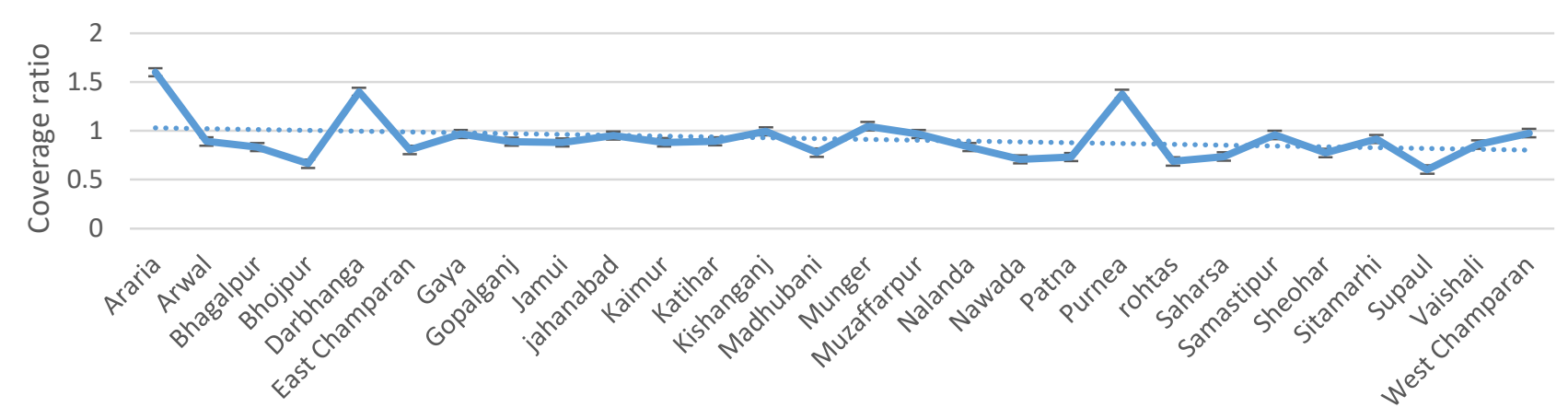

District names

\section{FIGURE 3A FOREST PLOT SHOWING COVERAGE RATIO AMONG DIFFERENT DISTRICTS Coverage ratio}

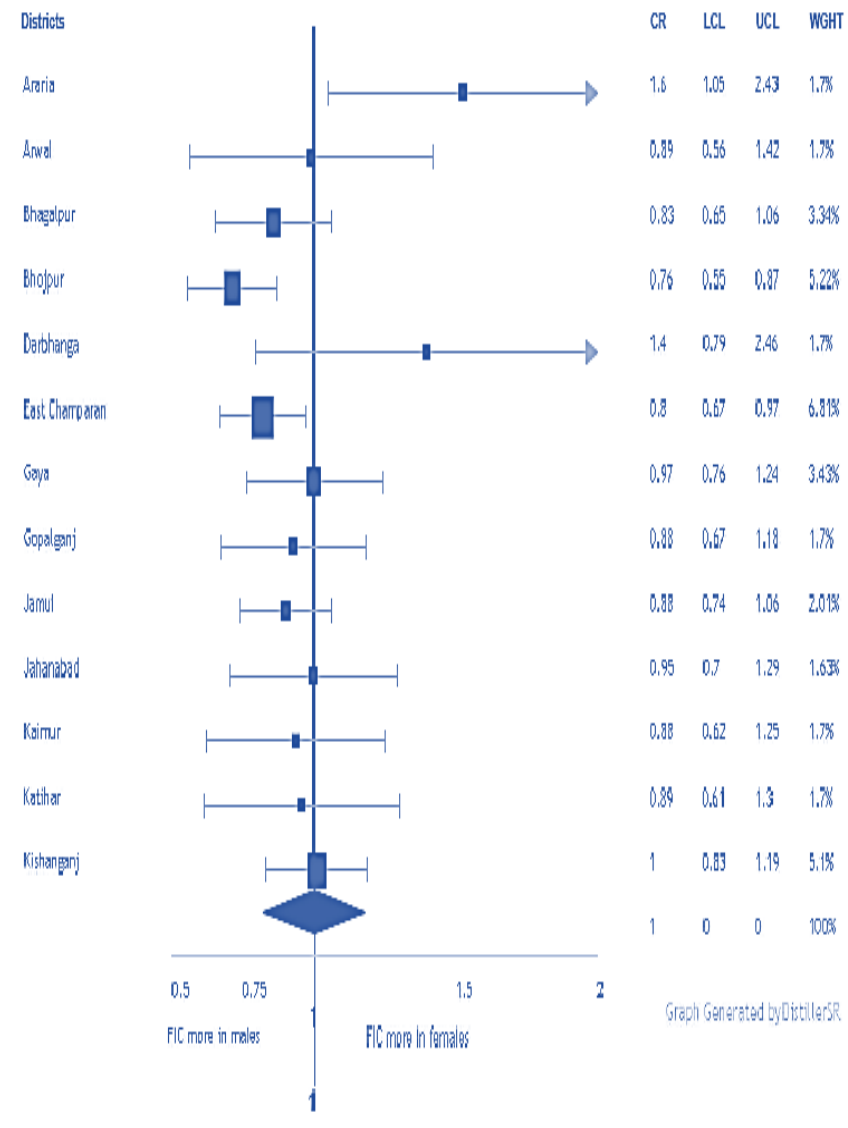

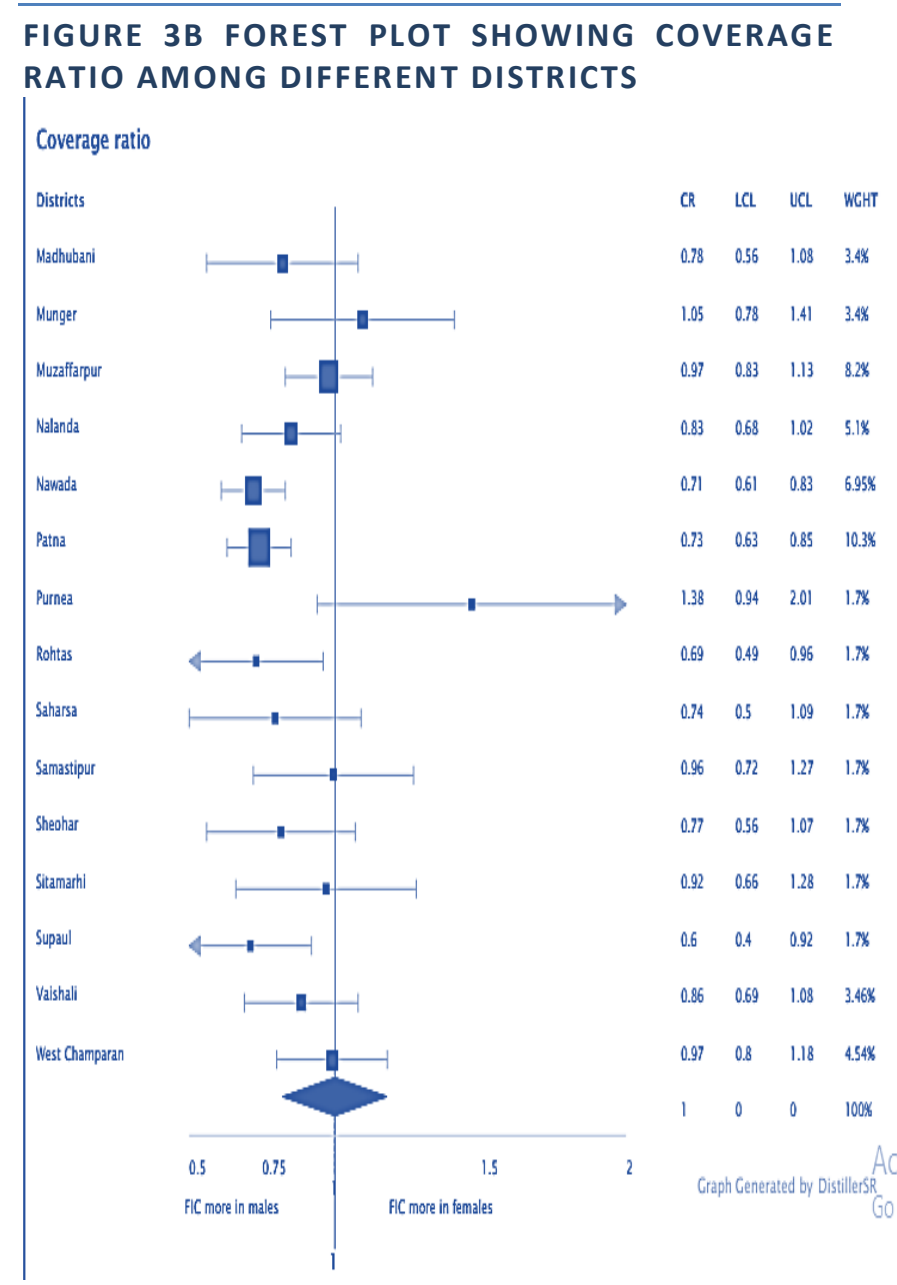

